\title{
Training Effectiveness from Guanxi Perspective in Mentoring System
}

\author{
Cheng-Hua,Tsai \\ Dept. of Tourism and Recreation, ChengShui University
}

No.840, Chengcing Rd., Niaosong Dist., Kaohsiung City 83347, Taiwan (R.O.C.),

E-mail: chenghua@csu.edu.tw

Ching-Hui,Tsai

Dept. of Fashion Design and Management, National Pingtung University of Science and Technology •

No 1, Shuefu Road, Neipu, Pingtung, Taiwan ( R.O.C. )

E-mail: chihuewy@yahoo.com.tw

\begin{abstract}
Ching-Yi, Tsai
Dept. of Educational Administration, National Pingtung University of Education No.4-18 Minsheng Rd., Pingtung City, Pingtung County 90003, Taiwan ( R.O.C. )

E-mail:chingyimaggie@yahoo.com.tw
\end{abstract}

Doi:10.5296/ijhrs.v4i1.5211

URL: http://dx.doi.org/10.5296/ijhrs.v4i1.5211

\begin{abstract}
This research is seeking to discuss how Guanxi influence training effectiveness between mentor and mentee. Two steps methods were used, first steps, from mentee to mentor using questionnaire, there are 150 questionnaires sent out 87 come back, sent to the hotel and hospitality department students. Second steps, focus group interviews were conducted with 5 informants in semi-structured, in-depth format and lasted approximately 120 minutes. From mentor to mentee using focus group interview, there are 5 different chef de cuisines. They have the classes with these students and also the students were by group gone to the restaurant for practical training. The result shows Guanxi influence trainees' reaction to training; it changes in job-related behavior and performance that result from training.
\end{abstract}

Keywords: Training Effectiveness, Guanxi, Mentoring System, Hospitality Industry

\section{Introduction}

The food service industry is considered to be a people enterprise because of its labor-intensive and service-oriented nature. How to offer and maintain the service quality, training plays a critical role, particularly in the hospitality industry where quality of service continues to be the most important characteristic differentiating a company form its competitors (Parnell, 2005). Especially, in chef training, mentor system is the most common to be adopted. In the past quarter of a century the literature has directed substantial attention 
at mentoring, which refers to an intensive developmental relationship between two individuals, the mentor and the protégé. In this relationship the mentor provides a range of career-instrumental (e.g. exposure and visibility to upper organizational echelons, protection, challenging assignments) and socio-emotional functions (e.g. friendship confirmation) for the protégé(Kramer, 1999).In hospitality industry especially among chefs, the concept of mentoring is typically associated with the traditional mentor-protégé dyad, a dyad in which the mentor is a more powerful and experienced member of the organization than the protégé(Hofstede, 1980).

Traditional mentoring relationships constitute one component of social capital (e.g. Bozionelos, 2003). Social capital is the product of all relationships ties the individual has and signifies resources (e.g. information, influence, solidarity) that the individual has at his or her disposal by means of the extensiveness and strength of these relationship ties. Network resource refers to the totality of an individual's interpersonal relationship ties excluding any traditional mentoring relationships (Bozionelos,2003). Parallel to the distinction between career-instrumental and socio-emotional mentoring functions, network resources have also been conceptually distinguished into instrumental and expressive.

Moreover, transfer of training the degree to which trainees apply to their jobs knowledge skills and behaviors learned in training is now widely acknowledge to be the paramount. Transfer climate has powerful influences to training transfer (Rouiller \& Goldstein, 1993). Transfer climate refers to those perceptions describing characteristics of the work environment that may facilitate or inhibit the use of trained skills. These characteristics can include immediate mentors' influence, the protégé attitudes toward training, and the extent of formal training policies and practices that exist to support training initiatives. Transfer climates may, therefore, be described as either supportive (i.e. favorable, positive) or unsupportive (i.e. unfavorable, negative) in relation to these characteristics.

Hypothesis 1: The better Guanxi between mentor and protégé, the transfer climate is lean toward supportive.

Guanxi, of all the positive outcomes of mentoring for protégés, influences the career success of protégés that has attracted the bulk of attention. Career success refers to the extrinsic and intrinsic achievements of individuals in their work-related lives(Hofstede, 1980).Extrinsic career achievements, referred to as extrinsic career success, pertain to objectively verifiable accomplishments(e.g. promotions achieved, salary); while intrinsic career achievements, referred to as intrinsic career success, pertain to individuals' own subjective evaluations of their accomplishments in their work-related lives. Hence, Guanxi as career success is usually explaining the longer term relationship. However, building good relationship takes a long time and energy to do it, for instance, frequent interactions with mentor after work. It might influence training quality because of good relationship, for example, not strict enough. As the result, the training effectiveness during training transfer, it is likely to be influence. Few studies exist that have dealt with the effectiveness of mentoring training programs. Little 
research has been done to operationalize and empirically assess training effectiveness factors that either facilitate or impede the quznxi in mentor training program. This lack of research may be attributed to the fact that many organizational variables that could influence employee performance have yet to be identified and measured (Kramer, 1999).

From learning theory - quanxi between student and teacher is like reverse V shape. Up to certain point

Hypothesis 2: Guanxi building might influence protégé learning effectiveness during training transfer.

The conceptual framework of this study

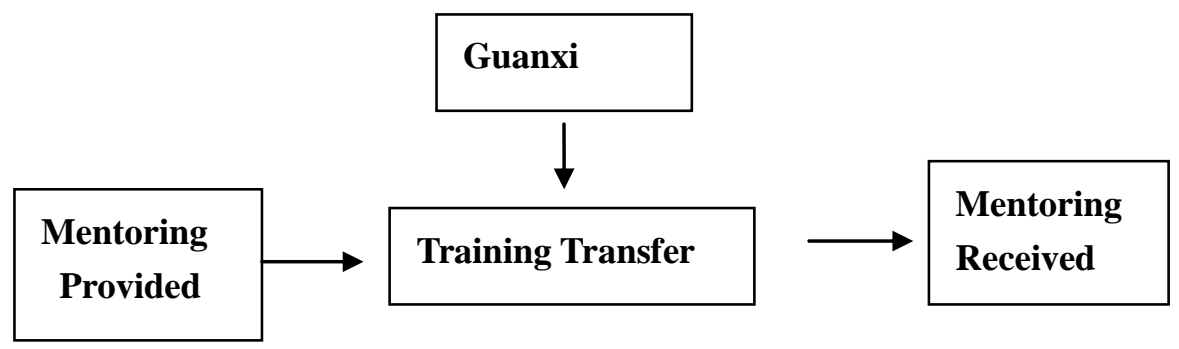

\section{Theoretical Background}

\section{2-1Mentoring and network resources}

Mentors are generally defined as individuals with advanced experience and knowledge who are committed to providing upward mobility and career support to their protégés. Network resources (Guanxi) refer to the totality of the individual's interpersonal ties or network, excluding the primary mentoring relationship. Therefore, network resources include multiple relationship ties of various strengths with other organizational members who can be of equal, lower or higher formal status than the focal individual. This includes the individual's developmental network which consists of all relationship ties that provide career and psychosocial support, including peer mentoring and of which the individual is aware of and the part of the individual's network that includes those relationship ties that assist career progression without the individual's full knowledge or awareness(Bozionelos 2003). A mentoring resource refers to an exclusive intensive relationship between the focal individual and a more powerful and experienced organizational member the mentor (Kramer, 1999). Voluminous empirical work has demonstrated the association of mentoring received by individuals in their organizational careers with extrinsic and intrinsic career success (Davern, 1997).

\section{2-2Learning transfer process}

There are two conceptual models to explain the learning transfer process. These two are based on Vroom's(1964) expectancy theory and Baldwin and Ford(1988) transfer of training model. Expectancy theory suggests that employees will be motivated at attend human resource development programs and try to learn from them if they believe:1) their efforts will result in learning the new skills or information presented in the program;2) attending the 
program and learning new skills will increase their job performance; and 3) doing so will help them obtain desired outcomes or prevent unwanted outcomes. On other hand, Baldwin and Ford's model asserts that the effectiveness of a training intervention is contingent upon many variables. Training design, trainee characteristics, and work environment characteristics are considered to be the most important sets of variables. Under the training design dimension one is concerned with principles of learning, sequencing of training content, and training content. Trainee characteristics refer to such personal traits as ability, personality and motivation. The work environment is in terms of the level of support the trainee receives from his or her supervisor and coworkers when acquiring and using new skills, knowledge, and behaviors. Further, under the work environment dimension, one is concerned with the extent to which the trainee has the opportunity to use and practice what he or she has learned in training.

In terms of research, the following factors have been found by researchers to facilitate the learning transfer process: self-efficacy; principles of learning used; ability; supervisory and coworker support for training; the similarity of training content with actual task performed; intrinsic and extrinsic rewards for using the newly learned skills and knowledge; training accountability; job utility and motivation to transfer(Ford et al., 1997).

However, there is a dynamic learning situation such as the relationship(quanxi) between mentor and protégé has not be addressed much

\section{2-3Guanxi and training transfer}

Guanxi(literally means relationship) has a significant impact and powerful implications in almost all aspects of relationships, especially in Chinese culture. Nevertheless, from the Western concept, this kind of relationship is mainly associated with "social friendships" or "family members" rather than with business partner. The focal unit of analysis for the Western concept of trainer and trainee relationship is the interorganizational level while that for the Chinese is first developed from the interpersonal level. The Western define a limited time span for the relationship, albeit long-term relationships are bounded by contractual terms. But, Chinese mentoring system can be lifelong obligations. These obligations require a full understanding of the role of guanxi in developing apprenticeship.

Moreover, there are cultural roots that make guanxi a principal moral criterion to evaluate individuals. The Confucian tradition defines individuals in relational terms(Yang,1994) such as father and uncle in the family, and teacher and master in one's career developments. Significant others in the Chinese context are not seen as instruments to help identify and recognize "self", a basic point of cognitive development theory reflecting western traditions of individualism and capitalism(Mead, 1934).

A basic characteristic of guanxi is familiarity or intimacy: for any two individuals to develop guanxi, they must know a good deal about each other and share a good deal with each other. In other words, guanxi develops between persons who are strongly rather than weakly tied. 
So guanxi is not merely a relationship but a tie through which the parties exchange valued materials or sentiments. Another characteristic of guanxi is trustworthiness, which is the result of relatively long-time interactions and the basis for future exchange relations. Because exchanges facilitated through guanxi networks are not formally or legally institutionalized, such trust is a necessary component of a guanxi connection (Wang, 2007).And relations between masters and apprentices and between teachers and students are considered father-son relations. There are not merely names people call each other; they set up a high moral standard that ties people together in a close relationship. Persons in these dyadic relationships are expected to help each other as if they are fulfilling obligations to their family members.

Guanxi is often translated into face (mianzi) and emotional feelings of attachment(ganqing). This means that reciprocity between strongly tied persons is intensified by added moral and expressive dimensions. On the other side, guznxi is rewarding and durable. When one helps one's guanxi, one raises one's reputation as having ganqing and wins thrust (face) from others. In doing so, one also puts debt on the beneficiary, who is in turn obligated to return a favor when requested. Applied this situation to training transfer in mentoring system, the guanxi between mentor and mentee would influence the learning transfer.

Guanxi refers to the network of informal relationships within a social group or, at an individual level, to a particular individual's informal relationship ties with other individuals within this social group. Guanxi literally means interpersonal relationships and in more practical terms it means "good connections" or network resources (Zhang, Y., \& Zhang, Z. 2006). It is distinguished into relationship ties with family members and relationship ties with non-family members. In additional, Guanxi relationships between non-family members are governed by the principle of reciprocity(Szeto \& Wright, 2006). If an individual receives a favor from another individual the former person is implicitly obliged to return a favor. It is, therefore, reasonable to assume that Guanxi, or network resources, provides, decisive assistance in the attainment of career success in the Chinese organizational environment, because it must enhance one's ability to receive favors that serve one's professional and career interests. Indeed, it has been noted that lack of Guanxi can make the acquisition of resources or the attainment of rewards very difficult (Szeto \& Wright, 2006).

\section{Network resources and Guanxi}

Network resources refer to the totality of the individual's interpersonal ties or network, excluding the primary mentoring relationship. Therefore, network resources include multiple relationship ties of various strengths with other organizational members who can be of equal, lower or higher formal status than the focal individual. This includes the individual's developmental network, which consists of all relationship ties that provide career and psychosocial support, including peer mentoring and of which the individual is aware of and the part of the individual's network that includes those relationship ties that assist career progression without the individual's full knowledge or awareness. 
3.Method

Two steps methods,first steps, from protégé to mentor using questionnaire, there are 150 questionnaire sent out 87 come back, sent to the hotel and hospitality department students.

Second steps, focus group interviews were conducted with 5 informants in semi-structured, in-depth format and lasted approximately 120 minutes. The interview guide was faxed or emailed to informants two days before interview. From mentor to protégé using focus group interview, there 5 different chef de cuisine. They have the classes with these students and also the students were by group went to the restaurant for practical training.

\section{Analysis and Discussion}

The moral philosopher Confucius who lived in the $6^{\text {th }}$ and $5^{\text {th }}$ centuries BC, have largely shaped the values of the Chinese society. A key Confucian teaching pertains to the nature of the mutual obligation between junior and senior members of a group. This may be any group, including the work organization, a work unit, friends, siblings or the family. According to Confucius, the senior members of the group are obliged to provide junior members with advice, consideration and protection; while the junior members of the group are obliged to show respect and obedience towards senior members(Hofstede,2001). This fundamental Confucian value strongly resembles the roles of mentor and protégé in a mentoring relationship. Therefore, the notion of mentoring is apparently part of the Confucian value system; and, hence, mentoring relationships should be an inherent part of all social contexts in China, including the work contest(Bozionelos and Wang 2006).

\section{4-1Training Effectiveness and Protégé performance}

Effective training program assess whether the participants acquire new skills during the training and whether they transferred their newly acquired skills to their job performance. Lo, M. C. M., \& Otis, E. M. (2003) established four primary criteria for evaluating the effectiveness of training programs. These criteria include(1) trainees' reaction to training, (2) knowledge acquisition, (3) changes in job-related behavior and performance that result from training, (4) improvements in organization-level results such as increased customer satisfaction and greater profitability.

Organizational and management circumstances back on the job also influence the degree of transfer. If there is seldom the opportunity to perform a task on the job that was taught in the training, then transfer will suffer? Similarly, the nature of support and reinforcement, as well as the kinds of problems present, can also impact the quality of transfer attained. The general climate of the workplace - whether it supports transfer or not - will also affect the degree to which transfer occurs beside Guanxi.

\section{Further Research Issues}

While some aspects of training design and practice seem to be undoubtedly showed by the research, there are a number of questions still waiting attention. 
This review of the transfer of training literature has some significant implications for the design and transfer of training programs.

The methods for measuring transfer of training are varied and often labor intensive. Usually they are designed for single-purpose research rather than on-going administrative use. Discovery methods that practitioners can more conveniently use that would also produce meaningful results would be a help to the field.

\section{References}

Baldwin, T.T., \& Ford, K.J. (1988). Transfer of training: A review and directions for future research. Personnel Psychology, 41, 63-105.

Bozionelos, N. (2003). Intra-organizational network resources: Relation to career success and personality. International Journal of Organizational Analysis, 11,41-66.

Bozionelos, N., \& Wang, L. (2006). The relationship of mentoring and network resources with career success in the Chinese organizational environment. The International Journal of Human Resource Management, 17(9), 1531-1546.

Davern, M. (1997). Social networks and economic sociology: A proposed research agenda for a more complete social science. American Journal of Economics and Sociology, 56(3), 287-302.

Ford, J. K. \& Weissbein, D. A. (1997). Transfer of training: An update review and analysis. Performance Improvement Quarterly, 10, 22-41

Hofstede, G. (1980). Culture's consequences: International differences in work-related values. Beverly Hills, CA: Sage Publications.

Kramer, R. (1999).Trust and distrust: Emerging questions, enduring questions. Annual Review of Psychology, 50, 569-591.

George Herbert Mead (1934). Mind, Self, and Society. Chicago: University of Chicago Press,

Lo, M. C. M., \& Otis, E. M. (2003). Guanxi civility: Processes, potentials, and contingencies. Politics \& Society, 31(1), 131-162.

Parnell, M. F. (2005). Chinese business guanxi: An organization or non-organization? Journal of Organisational Transformation \& Social Change, 2(1), 29-47.

Rouiller, J.Z. and Goldstein, I.L. (1993). The relationship between organizational transfer climate and positive transfer of training. Human Resources Development Quarterly, 4, 4, 377-390.

Szeto, R., \& Wright, P. C. (2006). Business networking in the Chinese context: Its role in the formation of guanxi, social capital and ethical foundations. Management Research News, 29(7), 425-438.

Vroom, V. H.(1964). Work and motivation. Oxford, England: Wiley.

Wang, C. L. (2007). Guanxi vs. relationship marketing: Exploring underlying differences. Industrial Marketing Management, 36(1), 81-86.

Zhang, Y., \& Zhang, Z. (2006). Guanxi and organizational dynamics in China: A link between individual and organizational levels. Journal of Busines Ethics, 67(4), 375-392. 